\title{
COMENTARIOS SOBRE "POR UN GIRO ANALÍTICO EN LA SOCIOLOGÍA" DE AGUIAR, DE FRANCISCO Y NOGUERA
}

\author{
Teresa González de la Fe \\ Universidad de La Laguna, Tenerife, España \\ tgdelafe@ull.es
}

Parece difícil no estar de acuerdo con el diagnóstico del estado actual de la sociología que realizan los autores. Pero una cosa es no estar satisfecha con la situación actual de la sociología, no sólo española, y otra distinta es "comprar" el pack de la sociología analítica que nos ofrecen Fernando Aguiar, Andrés de Francisco y José Antonio Noguera. Sin embargo, vaya por delante mi admiración y mi reconocimiento por haberse atrevido a dar a conocer esta especie de "manifiesto" que se nos ofrece para su debate en esta revista. Quede también patente mi agradecimiento y mi satisfacción por la invitación a la lectura y al comentario crítico de su invitación para la comunidad (las tribus, más bien) sociológica española. La crítica remueve las ideas y es bienvenida.

Coincidir con el diagnóstico no supone estar de acuerdo con el remedio y la receta. Los autores piden un giro analítico de la sociología, aunque por el camino estén dispuestos a desprenderse del adjetivo "analítico", pues lo importante no es llamarse "analítica", sino elaborar y practicar una ciencia social que, si nos atenemos a los puntos enumerados por los autores (precisión, coherencia, racionalidad, etc.), más que señalar una especificidad epistemológica y metodológica, apuntan al núcleo duro de cualquier conocimiento que se reclame científico, a diferencia del religioso, ideológico o de sentido común. Comparto estos principios, pero su formulación en este trabajo merece algunos comentarios y matices.

Es obvio que un conocimiento sistemático requiere precisión en las definiciones, y lo mismo puede decirse de la preocupación por la racionalidad del discurso y por el rigor lógico de la argumentación. Pero, cuando afirman que el análisis del lenguaje es una herramienta ineludible de toda ciencia, y aún más en el caso de la sociología al ser la puerta de acceso a la intencionalidad, si bien es difícil no estar de acuerdo, éste no implica aceptar concepciones de la intencionalidad y del lenguaje que no han sido especificadas en el artículo que comentamos. Y deberán aclararse en algún momento posterior, más allá de la apelación a la tradición de Tönnies y Simmel, sintetizada magistralmente por Max Weber, de la que también me reclamo heredera. Esto viene a cuento porque se declaran practicantes de una "actitud epistémica racionalista, en la mejor tradición sociológica" (p. 442), que queda un tanto ambigua.

Igualmente, cuando apuestan por la explicación causal en términos de mecanismos y microfundamentos, y se suman al intento de erradicación de las numerosas "cajas negras" existentes en los discursos habituales de la ciencia social, de nuevo hay poco espacio para la discrepancia en este tipo de afirmaciones genéricas. Dado que lo 
importante son los elementos que compongan el modelo de actor y lo que se consideren mecanismos y microfundamentos, la tradición de transmutar las razones esgrimidas por el sujeto para su acción en las causas de la misma, fue desechada tajantemente por Pareto hace ya mucho tiempo. Por ello, aunque es también obvio que la construcción teórica es una tarea inseparable de la explicación científicosocial, en mi opinión el problema sería, precisamente, la teoría del sujeto, que no queda clara en el "manifiesto". Poco hay que añadir al punto acerca de la formalización y el uso de modelos formales, pues, del mismo modo que vestir una bata no te convierte en científico, la modelización y la formalización no son más que un medio, nunca un fin, de la investigación.

Especial aplauso merece la afirmación de "la necesidad de tomar en serio los progresos y descubrimientos de las ciencias contemporáneas, de atreverse a considerar su relevancia para las ciencias sociales" (p. 443), al ser una propuesta novedosa y valiente en ambientes donde abunda cierto anticientifismo y se considera que las explicaciones científicas "deshumanizan", reducen a la persona a números u otras magnitudes de medida y argumentos de esta índole. En el homenaje al maestro Miguel Beltrán tuve ocasión de referirme a la necesidad de desarrollar en la sociología la "tercera cultura"', que no es integración del dualismo materia y espíritu en el que se debatían las Geisteswissenschaften y que no hacía sino esconder tensiones académicas corporativas de los profesores de la cambiante universidad alemana, sino la explicación por la ciencia de los temas que se consideraban exclusivos de las "humanidades" 0 "letras". El amor, la muerte, los dioses, los afectos y las pasiones, las creencias y los prejuicios, los valores y los temores, y un largo etcétera que normalmente se resume en las tres preguntas kantianas de quiénes somos, de dónde venimos y a dónde vamos. Las ciencias tienen ya muchas explicaciones para estas preguntas y éstas han de ser conocidas e integradas en la maistream sociology y formar parte del background de la teoría social contemporánea.

Dicho esto, lo que realmente constituye el "programa fuerte" del giro analítico al que se nos invita son sus cuatro principios de antipositivismo, pluralismo teórico y metodológico, historicismo y compromiso ético. La exposición y defensa de este programa, que constituye el núcleo propositivo del "manifiesto", me suscita algunas dudas y desconfianzas, pues los cimientos sobre los que se quiere edificar no parecen sólidos, con lo que el giro al que se nos invita puede convertirse en una pirueta (más) de la retórica sociológica. Dadas las limitaciones del espacio disponible, sólo atenderé al primero de los principios: el antipositivismo e invito a los autores a que organicen una segunda ronda de debates que remueva un poco las arenas de la sociología.

Para empezar, resulta curioso que un enfoque que reivindica la ciencia se declare "antipositivista", aunque esa etiqueta tan abusada en sociología durante el siglo XX, especialmente desde su último tercio en adelante, requiere una definición previa. La

\footnotetext{
${ }^{1}$ Gonzalez de la Fe, T. (2008), "Positivismo y antipositivismo", en Homenaje a Miguel Beltrán, Madrid, Centro de Investigaciones Sociológicas.
} 
etiqueta de "positivista" se ha convertido en una especie de insulto grave y descalificador. Sin embargo, el pensamiento positivo de Saint Simon y Comte del que deriva el epíteto actual, se denominó así para afirmar cosas, y no sólo demoler argumentos y descalificar situaciones inmorales e indeseables (González, 2008). Si los ilustrados usaron el "pensamiento negativo" para criticar el orden social e intelectual establecido incluida la autoridad epistemológica otorgada a las sagradas escrituras y al cuerpo burocrático teológico constituido en sus legítimos (y únicos) intérpretes, el 'pensamiento positivo' buscaba dejar atrás los esquemas mentales y argumentales propios de la religión (apelación a entidades o fuerzas sobrenaturales) y la metafísica (apelación a constructos ideales dotados de poderes), para usar los propios de las ciencias: el método científico como sistema y garantía del conocimiento. Por eso, la ciencia a la que apelaban los ilustrados era un fruto de la razón poseído por todo el género humano y no de la revelación intermediada de las divinidades. Esta democratización de las vías de acceso a la verdad implicó una revolución cultural y social cuyas consecuencias aún estamos viviendo, especialmente cuando las sociedades ricas actuales se autodefinen como sociedades del conocimiento.

Pero lo que los autores consideran una posición antipositivista es el acuerdo con cinco proposiciones que paso a comentar.

La primera es la cuestión del mentalismo, entendido como el requisito de que la teoría social requiere dar cuenta de los estados mentales de los individuos o sujetos. Mead, que denominó a su enfoque nada menos que "conductismo social", lo entendía como una teoría sociológica de la mente. Mead planteó su conductismo tomando como base la "entidad" (la mente o estados psicológicos internos de los sujetos) cuya negación constituía precisamente la seña de identidad de los conductistas tipo Watson o, posteriormente, Skinner. Aguiar, de Francisco y Noguera dicen que la sociología analítica atribuye estados mentales (tales como creencias, deseos o intenciones) a los agentes con objeto de explicar su conducta, lo que la sitúa como "sociología "comprensiva" en "el más puro sentido antipositivista weberiano" (p. 444). Es aquí donde la propuesta de la sociología analítica me parece un poco anticuada, pues ya Pareto señaló que las explicaciones que damos de nuestras acciones no son sino "derivaciones" a las que, erróneamente, atribuimos poder causal. Por ello, aunque el "poder causal" aportado por los "residuos" enunciados por Pareto sea más bien tosco y esté requerido de desarrollos empíricos, su teoría de las derivaciones supone un avance sustancial en la teoría de la acción, con un alcance más profundo que la solución weberiana, con la que también van a estar insatisfechos los lectores husserlianos de Weber como Schütz y los fenomenólogos ${ }^{2}$.

2 González de la Fe, T. (2003), "El interaccionismo simbólico" y "Sociología fenomelógica y etnometodología" en Salvador Giner (comp.) Teoría Sociológica moderna, Barcelona, Ariel. 
Abogar por el tibio mentalismo weberiano lleva a los autores a hacer una afirmación también sorprendente entre los defensores de la ciencia: la sociología analítica admite que entidades o hechos no directamente observables (que no son directamente reducibles a "datos de los sentidos") formen parte esencial de una explicación científicosocial.

¿No directamente observables significa en absoluto observables? ¿Cómo probamos nuestras afirmaciones? No queda esta cuestión suficientemente explicitada en el trabajo que comentamos. Máxime cuando a renglón seguido se añade que "en el núcleo de la sociología analítica está el rechazo de todo empirismo chato ... que intente basar las explicaciones sociológicas en meras correlaciones estadísticas entre variables" (p.445).

El antipositivismo analítico implica también buscar mecanismos sociales distintos a "leyes sociales", dado que mantienen una concepción local de la causalidad donde las causas se entienden como razones mentadas por el actor, con las deficiencias ya comentadas.

Por último, los autores señalan que las connotaciones ideológico-políticas que a veces se han atribuido al positivismo están fuera de lugar en el caso de la sociología analítica. Pese a no quedar claro si se refieren a la filiación de izquierdas de muchos integrantes del Círculo de Viena o al "empirismo abstracto" al que se refería Wright Mills, entiendo que la ciencia, natural y social, ha logrado ser compatible con ideologías de izquierda y de derechas, con todas las ambigüedades que estos términos arrastran. No quiere esto decir que sea moralmente indiferente, sino que su valor epistemológico no descansa ni puede descansar en sus principios éticos.

Para acabar, entiéndase que estas dudas están hechas "desde dentro", por así decirlo. No defiendo ni el positivismo al estilo de Comte o Stuart Mill, ni el neopositivismo del Círculo de Viena. Simplemente me parece que si es la hora de reivindicar a la sociología como ciencia social, bueno será hacerlo sin prejuicios ni complejos, sin que de nuevo se cuele la metafísica por la rendija. 